\title{
HOW BUSINESS CAN SUPPORT THE ResponsibILITY TO PROTECT
}

\author{
an OEF Research POLICY BRIEF \\ by Conor Seyle
39 one earth, F U T URE \\ R E S E A R C H
}

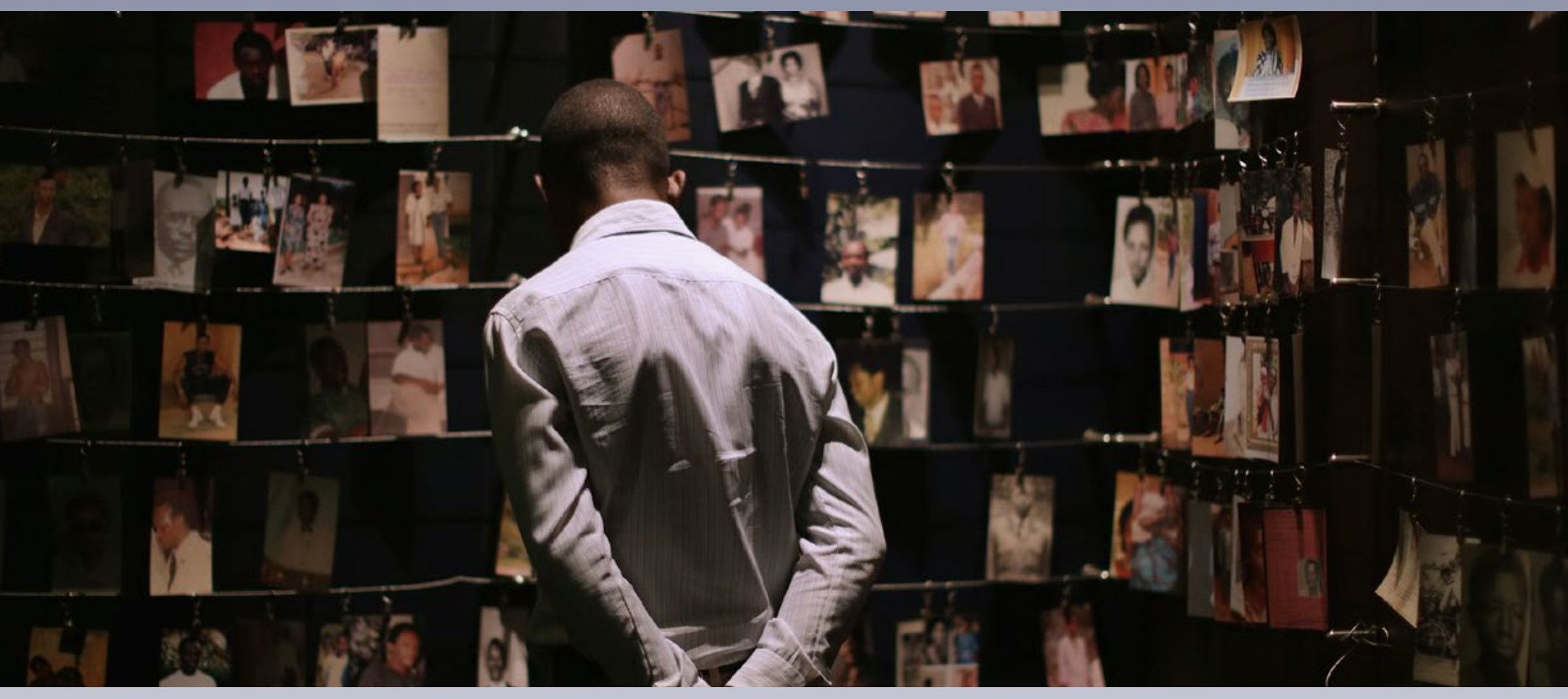

This policy brief, based on a book edited by One Earth Future researchers and fellows, explores the role of businesses as potential allies in supporting the Responsibility to Protect (R2P) principle.

\section{Policy Implications:}

Private sector actors, including individual businesses - and especially business associations representing groups of businesses - have economic and political reasons to support atrocity prevention and cessation. They may represent an untapped resource for assistance in supporting national or international interventions designed to stop or prevent atrocities.

There are demonstrable cases of private sector actors contributing to the mitigation, prevention, or cessation of atrocities. These include cases of business leaders working to protect individuals, companies contributing to messaging or diplomacy supporting peace and stability, and business associations working directly to engage in atrocity cessation.

$>$ Among a spectrum of potential activities, business actors may have particularly important roles in "upstream" or early identification of risks signaling an outbreak of atrocity, in supporting peaceful communication mechanisms that contribute to peace, and in supporting diplomacy as a neutral convener.

Day-to-day business operations can also contribute to peace and the prevention of atrocities by treating all employees and contractors fairly and creating access to economic opportunities. 


\section{HOW BUSINESS CAN SUPPORT THE RESPONSIBILITY TO PROTECT}

\section{RESEARCH SUMMARY}

The field of atrocity prevention took a significant step forward in the mid-2000s with the formal commitment of UN member states to the eradication of atrocities under the framing of the Responsibility to Protect. This commitment was formally adopted by UN members through the outcome document of the 2005 UN World Summit, and has been carried forward by Secretaries-General since then. The specific framing of the R2P commits member states to the eradication of atrocity crimesgenocide, ethnic cleansing, war crimes, and crimes against humanity-both within their borders and in other states. It is built around three pillars of action and commitment by member states: to prevent atrocities in their own territories, to assist other governments in meeting their obligations to prevent atrocity, and to take "timely and decisive action" to end atrocities occurring when

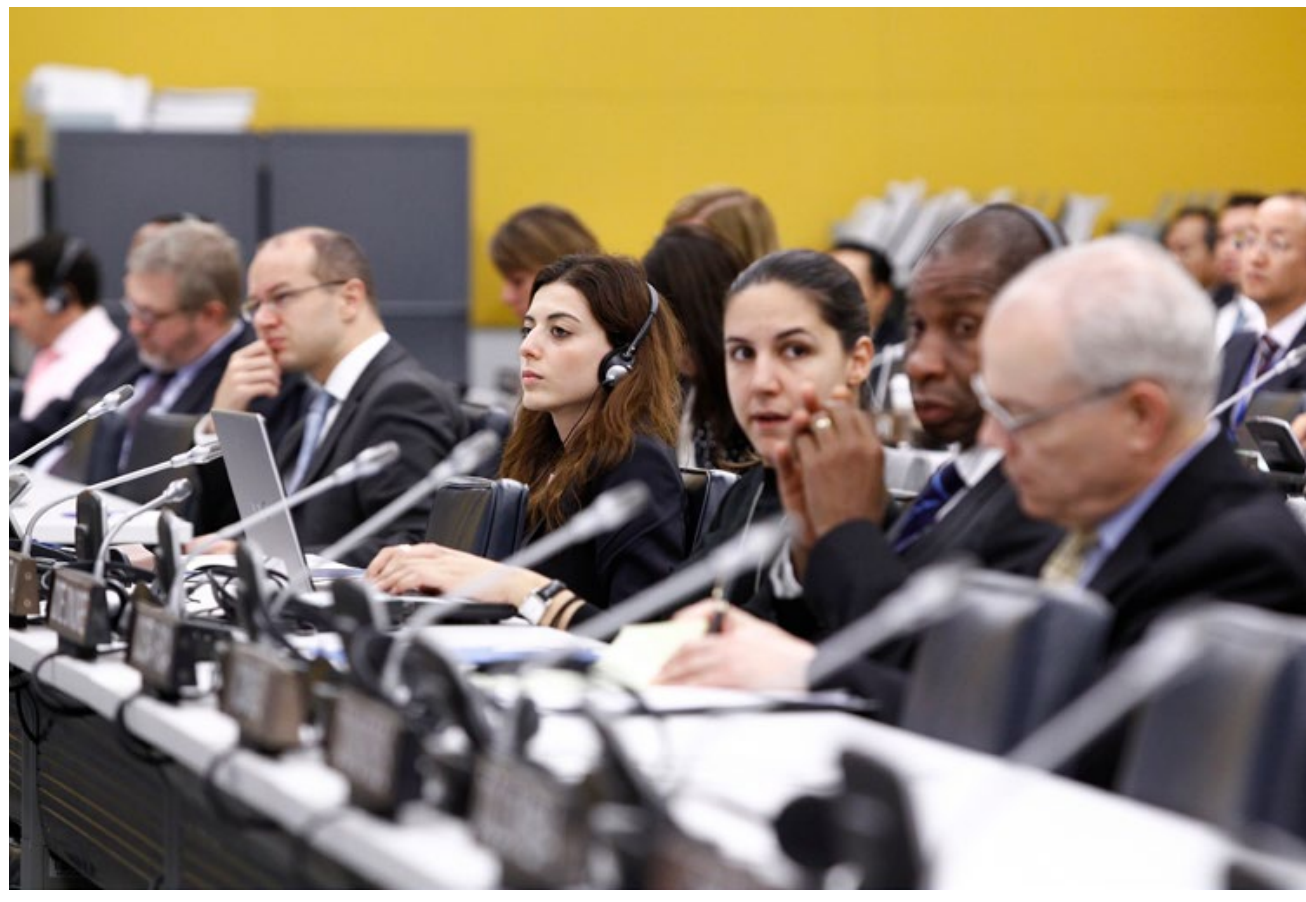

Audience at the General Asembly debates on the Responsibility to Protect. Photo byJC McIlwaine.

governments are unable or unwilling to prevent them.

Secretaries-General writing on R2P have acknowledged the role of non-state actors, especially civil society, in helping states live up to their obligations under R2P. Despite this, internationally, the policy discussion at the UN and in state capitals tends to focus heavily on state actions. Correspondingly, most of the public steps taken to address atrocity crimes tend to emphasize the tools that state actors can use: economic sanctions, legal pressures, and military interventions. These tools, while demonstrably effective, are also inevitably politically contentious and there has been significant debate over every intervention justified under R2P. Some states have raised concerns that the goals of R2P are twisted into attempts that are not honestly meant to address atrocity crimes, but are aimed at regime change in the narrow interests of some state actors.

The research collected in The Role of Business in the Responsibility to Protect suggests that the heavy focus on state activities, in addition to generating political issues, also may overlook important contributions non-state actors can play. This book focuses on the role of the private sector as a positive partner in atrocity prevention and cessation, and the chapters in the book both lay out theoretical frameworks for thinking about what this might look like, and document specific cases where private sector actors have contributed to atrocity prevention.

Kenya Pastoralist Journalist Network used peace initiatives on radio and in communal activities. Photo courtesy of World Association of Christian Communciation.

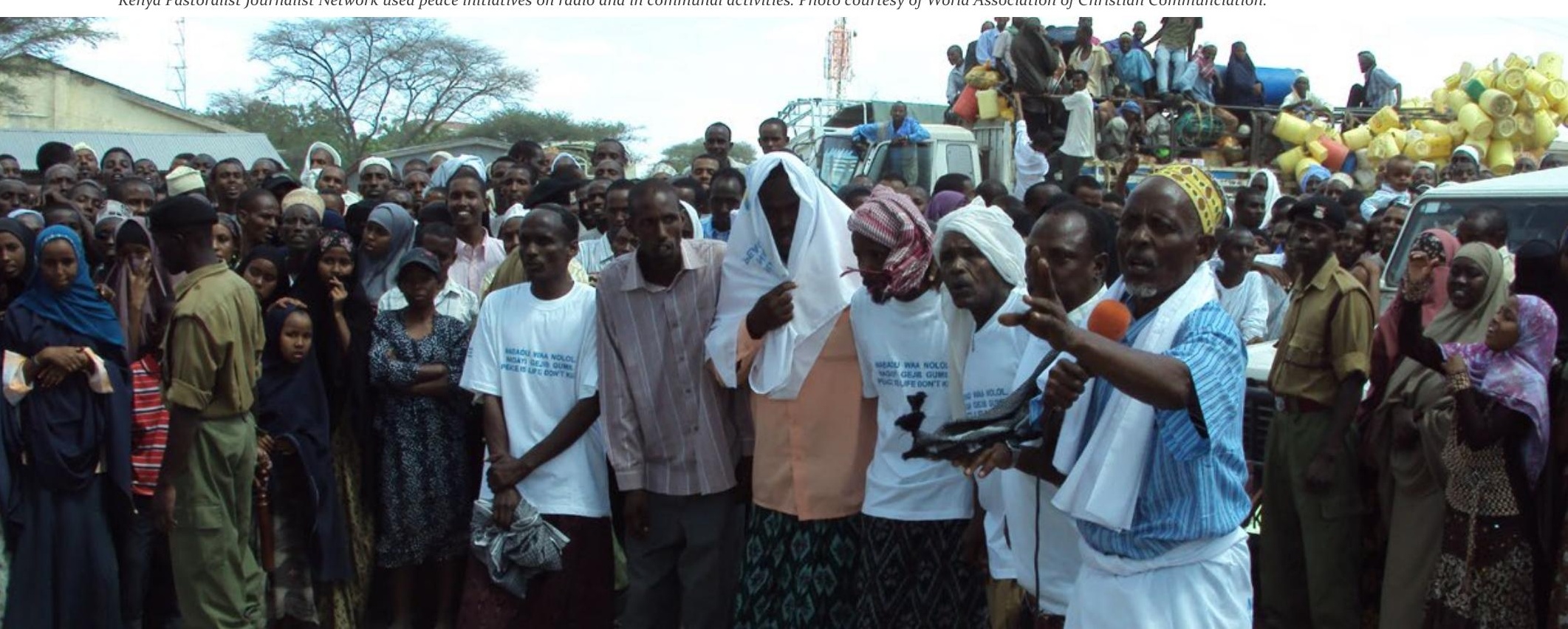


Some of the specific cases include a discussion on the role of private sector actors in Kenya in stopping and preventing postelection violence (ch. 5). In this case, actors including the local private sector association, as well as powerful individual companies, engaged in a coordinated campaign of private diplomacy and public messaging to help prevent conflict. Other chapters include descriptions of the role of business leaders in protecting civilians exposed to atrocity (ch. 3), and examinations of how telecommunications firms (ch. 7) and extractive companies (ch. 6) are particularly central to questions of atrocity prevention.

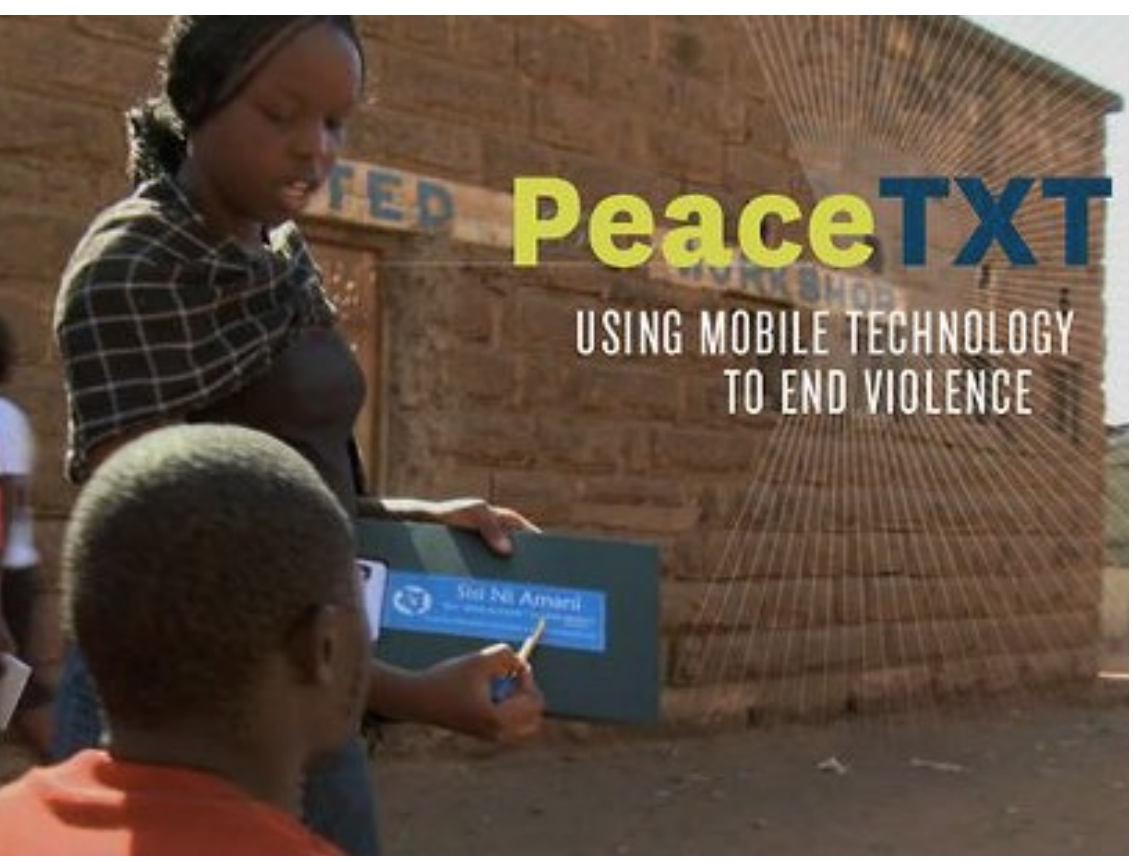

"Safaricom and Partners" by textually.org.
Collecting these case studies into more general frameworks, other chapters make the argument that private sector actors can play significant roles in intelligence gathering and early warning (ch. 4), or can engage in a range of activities from early engagement in prevention to direct or indirect protection of civilians and assistance with recovery (ch. 9). While these activities may or may not be decisive in stopping or preventing atrocities in and of themselves, they represent concrete contributions and ways to mobilize a relatively unengaged sector of society in contributing to atrocity prevention and cessation. In doing so, they offer another tool for state actors interested in R2P, and potentially a middle ground between a retreat from R2P entirely and a full commitment to military interventions and coercive programs as the only way to execute R2P. Broadening the spectrum of tools available to state actors may help to support the ongoing discussion around R2P by de-linking the current association between R2P as a concept and R2P as direct military action.

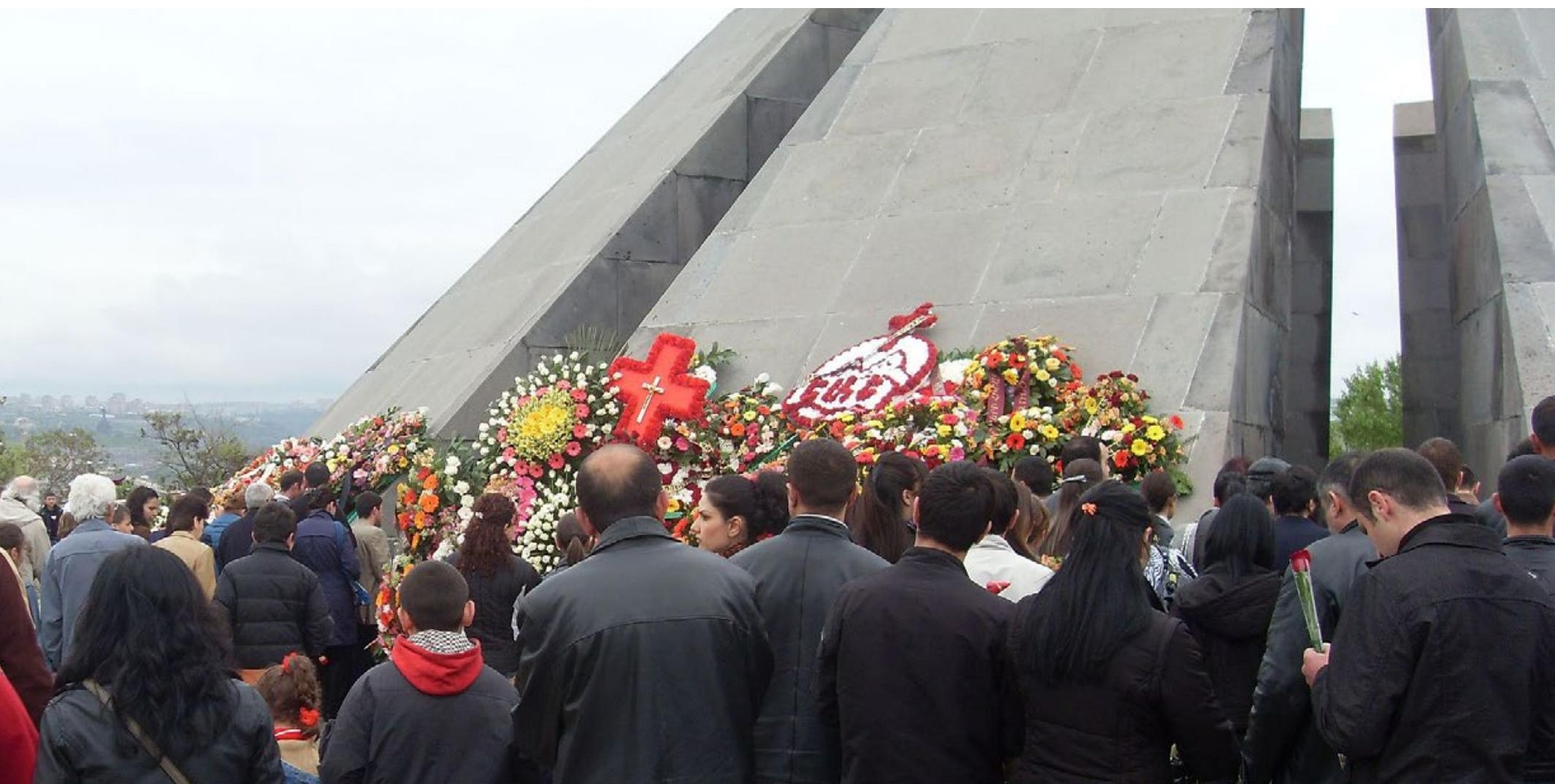




\section{BACKGROUND}

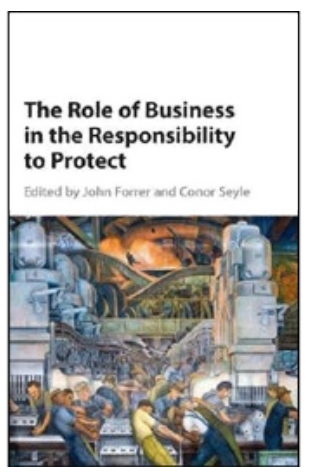

2. one earth F U T U R E

R E S E A R C H
A major contribution to the prevention and cessation of mass atrocities was the development of the "Responsibility to Protect" as a formal commitment by United Nations member states. Known as R2P, this principle clarified member states' commitment under international law to prevent and stop atrocities within their own borders and elsewhere. Since its inception, R2P has been controversial, and there has been debate over how to operationalize and support this principle. A recent book edited by One Earth Future researchers and fellows, The Role of Business in the Responsibility to Protect, examines one question relating to supporting R2P: What could be the role of the private sector in preventing atrocities and driving global commitment to this norm?

Available through Cambridge University Press. ISBN: 9781107156128

OEF Research, a program of the One Earth Future Foundation, believes that policy and practice reflect the quality of available information. We promote empirically-informed research developed using methodologically rigorous approaches as a tool for policy making in peace, security, and good governance. It believes in analyzing evidence using both quantitative and qualitative best practices. We also believe the most innovative solutions to problems of conflict and peace necessarily involve a diverse set of disciplinary and sectoral viewpoints. Much of our work aims to break down the barriers between these different perspectives.

For more information, visit oefresearch.org 